\title{
Platelet Distribution width is an Early Indicator of Acute Coronary Syndrome
}

\author{
SILPI PERVIN ${ }^{1}$, MD. SAIFUL ISLAM ${ }^{2}$, SHEULY FERDOUSHI ${ }^{2}$, MOSHARAF HOSSAIN $^{3}$, TUHIN SULTANA ${ }^{2}$, MD. \\ HARISUL HOQUE ${ }^{4}$, CHOWDHURY MESHKAT AHMED ${ }^{4}$, A.N. NASHIMUDDIN AHMED ${ }^{2}$ \\ ${ }^{1}$ Department of Pathology, MH Samorita Medical College, Dhaka, ${ }^{2}$ Department of Clinical Pathology, Bangabandhu Sheikh \\ Mujib Medical University, Dhaka, ${ }^{3}$ Department of Medicine, Shahid Shorwardi Medical College, Dhaka, ${ }^{4}$ Department of \\ Cardiology, Bangabandhu Sheikh Mujib Medical University, Dhaka \\ Address of Correspondence: Dr. Silpi Pervin, Assistant professor, Department of Pathology, \\ MH Samorita Medical College, Dhaka. E mail: silpioervin@gmail.com.
}

\begin{abstract}
:
Objective: This cross sectional study was conducted in the dept. of clinical pathology in collaboration with dept. of cardiology, Bangabandhu Sheikh Mujib Medical University (BSMMU) and Bangladesh Institute of Research \& Rehabilitation of Diabetes Endocrine and Metabolic Disorders (BIRDEM) to evaluate the role of platelet distribution width (PDW) in diagnosing acute coronary syndrome (ACS). Patients \& Methods: A total of 142 patients were selected for the study. Of them 79 were cases (patients with acute coronary syndrome) and 63 were controls (patients with non cardiac chest pain). The cardiologist established the diagnosis by clinical examination, ECG and biochemical markers especially troponin I. A structured questionnaire was used which addressed all the variables of interest. Blood samples of the selected patients were taken to investigate their platelet distribution width level and to find its association with ACS. The blood samples was taken properly and processed in a Haematology auto analyzer within 2 hours of collection, which again rechecked manually by peripheral blood film. Statistical analyses were done using mean \pm standard deviation (SD), t-test, Chi-square (x2) with $95 \%$ confidence interval. Test of validity done by receiver operative characteristic curves. Result: In the present study, platelet counts were $273.1 \pm 50.15 \times 10^{9} / \mathrm{L}$ in patients with ACS and 290.78 $\pm 74.86 \times 10^{9} / \mathrm{L}$ in control subjects. Platelet counts were slightly low in patients with ACS compared to control subjects. There were no statistical significant differences between the groups in unpaired t- tests. MPV was $12.48 \pm 1.17 \mathrm{fl}$ and $10.45 \pm 0.66 \mathrm{fl}$ in patients with ACS and control subjects. PDW was $16.23 \pm 2.56$ fl and 11.89 \pm 1.42 fl in patients with ACS and control subjects. Both MPV and PDW were statistically significant between the groups $(P<0.001)$ in unpaired $t$-test. Patients with acute coronary syndrome the sensitivity, specificity, positive predictive value and negative predictive value of platelet counts, MPV and PDW were obtained by ROC curve and compared with control subjects. The best cut off value of platelet count, MPV \& PDW were $>225 \times 10^{9} / \mathrm{L},>10.7 \mathrm{fl}$ and $>12.7$ fl respectively. The sensitivity, specificity, accuracy, positive and negative predictive value of platelet counts, MPV and PDW were 83\%, 28.1\%, 42.3\%, 37.6\%, $64 \% ; 90.6 \%, 49.4 \%, 64.8 \%, 51.6 \%, 89.8 \%$; and $94.3 \%, 52.8 \%, 69 \%, 54.9 \%, 94.1 \%$ respectively. In our study, we found that PDW had higher sensitivity and specificity in contrast to MPV. These PDW are used as predictor for early detection of ACS and risk stratification when other cardiac biomarkers are negative. Conclusion: The PDW is an early indicator to diagnose ACS and correlates with the prognosis of ACS.
\end{abstract}

Key words - Platelet distribution width, acute coronary syndrome.

Introduction:

Diagnosis of acute coronary syndrome is still a challenge, despite the remarkable improvement in the diagnostic modalities ${ }^{1}$. Disease of the coronary arteries is usually due to atheroma and its complications, particularly thrombosis. The culprit lesion is usually a complex ulcerated or fissured atheromatous plaque with adherent platelet rich thrombus and local coronary artery spasm. The thrombus may undergo spontaneous lysis over the next few days although by this time irreversible myocardial damage has occurred. The process of infarction progress over several hours and most patients present when it is still possible to salvage myocardium and improveout ${ }^{2}$. Platelet has been implicated in the pathogenesis of cardiovascular disorders ${ }^{3}$ where platelet activation and thrombus formation is necessary. ${ }^{4}$ Without platelet activation development of acute coronary syndrome (ACS) is impossible. ${ }^{5}$ Platelet activation and aggregation play a key role in initiating and propagating coronary artery thrombosis ${ }^{6}$. Activated platelet become change its 
morphology which can be determine by platelet distribution width (PDW) and also larger in size, this changes can be measured by both PDW and mean platelet volume (MPV). ${ }^{7}$ Platelet indices such as PDW and MPV may be useful to show the association between platelet size and ischemic events. ${ }^{8}$ The activated platelet is thought to be the major biological risk factor for pathogenesis of ACS. Inhibition of this process could play an important role in prevention of cardiovascular disease. ${ }^{9}$

PDW is a quantitative measure of platelet size variation. An increased PDW indicate more variation of size (anisocytosis) which result from formation of pseudopodia and may be the predictor of platelet activation and turnover. PDW is more sensitive and specific than MPV in terms of platelet reactivity. ${ }^{10} \mathrm{PDW}$ is less explored in Bangladesh; no effective study was done to see the role of PDW in detection of ACS in Bangladesh.

\section{Material and methods:}

This cross sectional study conducted in Department of Clinical Pathology, in collaboration with Department of Cardiology, BSMMU and BIRDEM from September 2011 to August 2012. A total 142 adults (18 years above) Patients with clinically suspected acute coronary syndrome who were attended in cardiac emergency and admitted in coronary care unit (CCU) in the department of Cardiology, BSMMU, and BIRDEM, Dhaka were enrolled in this study. Among 79 patients were included in this study as cases (group I). They have ECG changes (ST-elevation, ST-depression, Tinversion, appearance of Q-wave), with or without troponin I positive and rest of 63 patients comprises as controls (group II) those have normal ECG findings, and cardiac marker troponin I was negative. Clinical history, medical reports, findings and information were documented in a pre designed data sheet with inform and written consent with help of ECG report. Some patients are dropped out from this study.
Known case of patients with congenital heart disease, hepatic and renal impairment, documented malignancy, with anti-platelet, anti-coagulants, anti-inflammatory therapy, lipid lowering agents and traumatic chest pain were excluded from this study.

CBC with PBF including platelet, ESR, platelet parameters (MPV \& PDW), troponin I, serum creatinine, fasting blood glucose, lipid profile, SGPT were done for case selection. About $5.0 \mathrm{ml}$ blood was collected from each patient after admission (before antiplatelet therapy) through an aseptic venipuncture from antecubital vein. From these $2.0 \mathrm{ml}$ of that blood was collected in EDTA tube for complete blood count (CBC) and peripheral blood film (PBF). $3.0 \mathrm{ml}$ blood was transferred into a clean, dry test tube and was centrifuged within an hour of collection to separate the clear serum. Complete blood count (CBC) and platelet parameters were estimated by automated Haematology autoanalyzer (SYSMEX-XT 4000i) within 2 hours which again rechecked manually by peripheral blood film.

Prior to the commencement of this study, the research protocol was approved by the Institutional Review Board (IRB) of BSMMU, Dhaka. Data were processed and analyzed by using computer software SPSS (Statistical package for social sciences version 17) by applying appropriate formula. The test statistics used to analyze the data was mean \pm standard deviation (SD), t-test, and Chi-square test with $95 \%$ confidence interval. Test of validity done by receiver operative characteristic analysis curves.

\section{Results:}

A total of 142 patients were included in this study. Maximum 33(41.8\%) and 25 (39.7\%) patients age belonged to 51-60 years age group and mean age was found $55.05 \pm 10.73$ and 54.510 .39 years in group I and in group II (Table $-\mathrm{I}$ ) . The mean age difference was not

Table-I

Age distribution of the study patients $(n=142)$

\begin{tabular}{|c|c|c|c|c|c|}
\hline \multirow[t]{2}{*}{ Age (in years) } & \multicolumn{2}{|c|}{$\begin{array}{l}\text { Group I } \\
(\mathrm{n}=79)\end{array}$} & \multicolumn{2}{|c|}{$\begin{array}{c}\text { Group II } \\
(\mathrm{n}=63)\end{array}$} & \multirow[t]{2}{*}{$P$ value } \\
\hline & $\mathrm{N}$ & $\%$ & $\mathrm{n}$ & $\%$ & \\
\hline $31-40$ & 9 & 11.4 & 6 & 9.5 & \\
\hline $41-50$ & 17 & 21.5 & 22 & 34.9 & \\
\hline $51-60$ & 33 & 41.8 & 25 & 39.7 & \\
\hline $61-70$ & 14 & 17.7 & 8 & 12.7 & \\
\hline$>70$ & 6 & 7.6 & 2 & 3.2 & \\
\hline Mean \pm SD & 55.05 & \pm 10.73 & 54.5 & \pm 10.39 & $0.681^{\mathrm{ns}}$ \\
\hline Range (min-max) & \multicolumn{2}{|c|}{$(31-80)$} & \multicolumn{2}{|c|}{$(31-78)$} & \\
\hline
\end{tabular}

Group I: Patients having acute coronary syndrome

Group II: Patients without acute coronary syndrome ns= non significant

$\mathrm{P}$ value reached from unpaired t-test 
statistically significant $(\mathrm{P}>0.05)$ between the groups. Male was predominant in both groups and 57(72.2\%) male in group I, and 44 (69.8\%) in group II (fig. 1). Regarding the baseline characteristics of the study patients, in CBC



Fig.-1: Bar diagram showing the sex distribution of the study patients.

parameters, only mean neutrophil percentage and ESR difference was statistically significant $(\mathrm{P}<0.05)$ but WBC count was not statistically significant $(\mathrm{P}>0.05)$ between the groups and triglyceride, total cholesterol and LDL cholesterol was statistically significant ( $p=0.001$ ) but HDL cholesterol was not statistically significant $(\mathrm{p}=0.668)$ (Table II). Troponin I was found positive in 53(67.1\%) patients in group I but none in group II. The difference was statistically significant $(\mathrm{P}<0.05)$ between the groups (Table III) and in ECG findings, myocardial infarction was found $67(84.8 \%)$ patients, and UA in 12(15.2\%) patients in group I and all ECG was found normal in all $63(100.0 \%)$ cases in group II. The difference was statistically significant $(\mathrm{P}<0.05)$ between the groups.
Table IV showed the mean ( \pm SD) of platelet counts, MPV and PDW in patients in group I, and subjects in group II. The mean $\left( \pm\right.$ SD) platelet count was $273.1( \pm 50.15) 10^{9} / \mathrm{L}$ and $290.78( \pm 74.86) 10^{9} / \mathrm{L}$ in group I and group II respectively and there was no statistical significant found between the groups $(\mathrm{P}=0.096)$. The mean $( \pm \mathrm{SD}) \mathrm{MPV}$ was $12.48( \pm 1.17) \mathrm{fl}$ and in-group II, MPV was $10.45( \pm 0.66) \mathrm{fl}$, and these was statistically significant $(\mathrm{P}=0.001)$. The mean $( \pm \mathrm{SD})$ PDW was $16.23( \pm 2.56) \mathrm{fl}$ and $11.89( \pm 1.42) \mathrm{fl}$ in group I and group II respectively and these was statistically significant $(\mathrm{P}=0.001)$. Receiver-operator characteristic (ROC) curves of platelet count, MPV and PDW for prediction of acute coronary syndrome (ACS).The area under the receiver-operator characteristic (ROC) curves for the ACS predictors by troponin I is depicted in table V. Based on the receiver-operator characteristic (ROC) curves PDW had the best area under curve compared to platelet counts and MPV evaluated by troponin I. Receiver-operator characteristic (ROC) were constructed using PDW value of the patients between two groups, which gave a PDW cut off value of $>12.7 \mathrm{fl}$ as the value with a best combination of sensitivity and specificity for acute coronary syndrome. At this PDW cut-off value of $>12.7 \mathrm{fl}$, the sensitivity and specificity of PDW in diagnosing acute coronary syndrome was found $94.3 \%$ and $52.8 \%$, respectively (Fig 2). Platelet count cut-off value of $>225 \times 10^{9} / \mathrm{L}$ showed sensitivity $83.0 \%$ and specificity $28.1 \%$ in the diagnosis of acute coronary syndrome. MPV cut-off value of $>10.7 \mathrm{fl}$ showed sensitivity $90.6 \%$ and specificity $49.4 \%$ in the diagnosis of acute coronary syndrome.

Table-II

Distribution of the study patients according to Lab parameters $(n=142)$.

\begin{tabular}{|c|c|c|c|}
\hline Lab parameters & $\begin{array}{c}\text { Group } \mathrm{I}(\mathrm{n}=79) \\
\text { Mean } \pm \mathrm{SD}\end{array}$ & $\begin{array}{c}\text { Group II(n=63) } \\
\text { Mean } \pm S D\end{array}$ & $P$ value \\
\hline $\begin{array}{l}\text { WBC }\left(10^{9} / \mathrm{L}\right) \\
\text { Range (min-max) }\end{array}$ & $\begin{array}{c}11.87 \pm 3.65 \\
(6-35)\end{array}$ & $\begin{array}{c}10.73 \pm 9.37 \\
(4-80)\end{array}$ & $0.323^{\text {ns }}$ \\
\hline $\begin{array}{l}\text { Neutrophil (\%) } \\
\text { Range (min-max) }\end{array}$ & $\begin{array}{c}68.01 \pm 7.97 \\
(45-90)\end{array}$ & $\begin{array}{c}62.38 \pm 12.26 \\
(40-88)\end{array}$ & $0.001^{\mathrm{s}}$ \\
\hline $\begin{array}{l}\mathrm{ESR}\left(\mathrm{mm} / 1^{\text {st }} \text { hour}\right) \\
\text { Range (min-max) }\end{array}$ & $\begin{array}{c}36.91 \pm 22.44 \\
\quad(5-120)\end{array}$ & $\begin{array}{c}23.39 \pm 24.29 \\
\quad(5-120)\end{array}$ & $0.001^{\mathrm{s}}$ \\
\hline Lipid profile & & & \\
\hline $\begin{array}{l}\text { Triglyceride (mg/dl) } \\
\text { Range (min-max) }\end{array}$ & $\begin{array}{l}146.67 \pm 31.74 \\
(86-230)\end{array}$ & $\begin{array}{l}122.89 \pm 35.37 \\
(78-210)\end{array}$ & $0.001^{\mathrm{s}}$ \\
\hline $\begin{array}{l}\text { Cholesterol (mg/dl) } \\
\text { Range (min-max) }\end{array}$ & $\begin{array}{l}177.62 \pm 34.43 \\
(95-240)\end{array}$ & $\begin{array}{l}135.35 \pm 40.15 \\
(70-230)\end{array}$ & $0.001^{\mathrm{s}}$ \\
\hline $\begin{array}{l}\text { HDL (mg/dl) } \\
\text { Range (min-max) }\end{array}$ & $\begin{array}{c}39.06 \pm 7.3 \\
(23-58)\end{array}$ & $\begin{array}{c}38.52 \pm 7.62 \\
(23-56)\end{array}$ & $0.668^{\text {ns }}$ \\
\hline $\begin{array}{l}\text { LDL (mg/dl) } \\
\text { Range (min-max) }\end{array}$ & $\begin{array}{c}124.9 \pm 23.44 \\
(61.3-185)\end{array}$ & $\begin{array}{c}79.84 \pm 16.65 \\
(54-140)\end{array}$ & $0.001^{\mathrm{s}}$ \\
\hline
\end{tabular}

$\mathrm{s}=$ significant, $\mathrm{ns}=$ not significant

$\mathrm{P}$ value reached from unpaired t-test 
Table-III

Baseline characteristics of the study patients $(n=142)$

\begin{tabular}{|c|c|c|c|c|c|}
\hline \multirow[t]{2}{*}{ Baseline characteristics } & \multicolumn{2}{|c|}{$\begin{array}{l}\text { Group I } \\
(\mathrm{n}=79)\end{array}$} & \multicolumn{2}{|c|}{$\begin{array}{c}\text { Group II } \\
(\mathrm{n}=63)\end{array}$} & \multirow[t]{2}{*}{$P$ value } \\
\hline & $\overline{\mathrm{N}}$ & $\%$ & $\mathrm{n}$ & $\%$ & \\
\hline \multicolumn{6}{|l|}{ Hypertension } \\
\hline Yes & 37 & 46.8 & 11 & 17.5 & $0.001^{\mathrm{s}}$ \\
\hline No & 42 & 53.2 & 52 & 82.5 & \\
\hline \multicolumn{6}{|l|}{ ECG } \\
\hline Myocardial infarction (MI) & 67 & 84.8 & 0 & 0.0 & \\
\hline Unstable angina (UA) & 12 & 15.2 & 0 & 0.0 & $0.001^{\mathrm{s}}$ \\
\hline Normal & 0 & 0.0 & 63 & 100.0 & \\
\hline \multicolumn{6}{|l|}{ Troponin I } \\
\hline Positive & 53 & 67.1 & 0 & 0.0 & $0.001^{\mathrm{s}}$ \\
\hline Negative & 26 & 32.9 & 63 & 100.0 & \\
\hline
\end{tabular}

$\mathrm{s}=$ significant, $\mathrm{ns}=$ not significant, $\mathrm{P}$ value reached from chi- square test

Table-IV

Mean platelet count, MPV and PDW of the study patients $(n=142)$

\begin{tabular}{lccc}
\hline Variables & $\begin{array}{c}\text { Group I }(\mathrm{n}=79) \\
\text { Mean } \pm \text { SD }\end{array}$ & $\begin{array}{c}\text { Group II }(\mathrm{n}=63) \\
\text { Mean } \pm \text { SD }\end{array}$ & $P$ value \\
\hline Platelet count $\left(10^{9} / \mathrm{L}\right)$ & $273.1 \pm 50.15$ & $290.78 \pm 74.86$ & $0.096^{\mathrm{n}}$ \\
Range (min-max) & $(190-450)$ & $(150-610)$ & \\
& & & \\
MPV (fl) & $12.48 \pm 1.17$ & $10.45 \pm 0.66$ & $0.001^{\mathrm{s}}$ \\
Range (min-max) & $(9.20-16.2)$ & $(9.1-12.5)$ & \\
& & & $0.001^{\mathrm{s}}$ \\
PDW (fl) & $16.23 \pm 2.56$ & $11.89 \pm 1.42$ & \\
Range (min-max) & $(10.1-25.6)$ & $(9.7-16.5)$ & \\
\hline
\end{tabular}

$\mathrm{s}=$ significant

ns= not significant

$\mathrm{P}$ value reached from unpaired t-test

Table-V

Receiver-operator characteristic (ROC) curve of platelet count, MPV and PDW for prediction of acute coronary syndrome.

\begin{tabular}{lccccccccc}
\hline & $\begin{array}{c}\text { Cut } \\
\text { of value }\end{array}$ & $\begin{array}{c}\text { Sensitivity } \\
(\%)\end{array}$ & $\begin{array}{c}\text { Specificity } \\
(\%)\end{array}$ & $\begin{array}{c}\text { Accuracy } \\
(\%)\end{array}$ & PPV (\%) & NPV (\%) & \multicolumn{2}{c}{$\begin{array}{c}\text { Area under } \\
\text { the ROC curve }\end{array}$} & \multicolumn{2}{c}{$\begin{array}{c}\text { 95\% Confidence interval (CI) } \\
\text { Lower bound }\end{array}$} & Upper bound \\
\hline Platelet count & $>225\left(10^{9} / \mathrm{L}\right)$ & 83.0 & 28.1 & 42.3 & 37.6 & 64.0 & 0.428 & 0.333 & 0.524 \\
MPV & $>10.7(\mathrm{fl})$ & 90.6 & 49.4 & 64.8 & 51.6 & 89.8 & 0.824 & 0.754 & 0.895 \\
PDW & $>12.7(\mathrm{fl})$ & 94.3 & 52.8 & 69.0 & 54.9 & 94.1 & 0.846 & 0.780 & 0.912 \\
\hline
\end{tabular}

$\mathrm{PPV}=$ Positive predictive value

$\mathrm{NPV}=$ Negative predictive value 


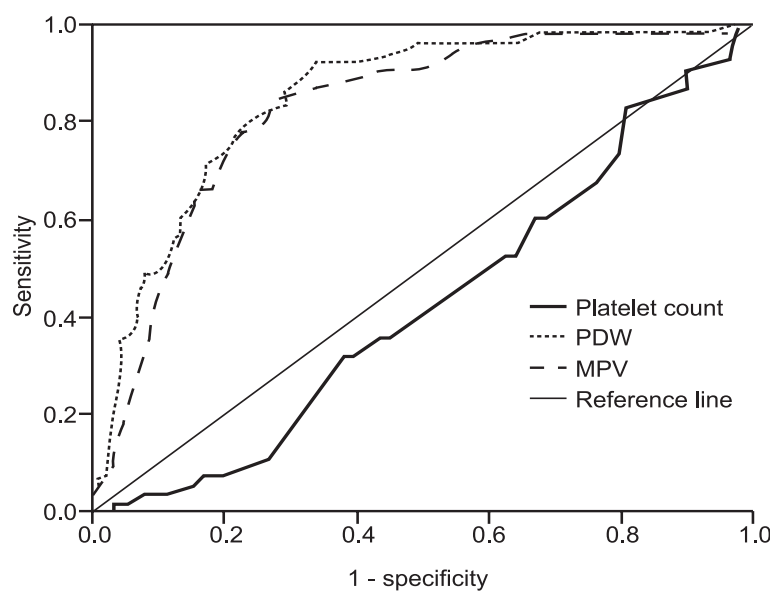

Fig.-2: Receiver-operator characteristic curves of platelet count, MPV and PDW.

\section{Discussion:}

Acute coronary syndromes (ACS) are a set of signs and symptoms due to rupture of a plaque and are a consequence of platelet rich coronary thrombus formation. ${ }^{11}$ Though the improvement of treatment and primary prevention, ACS is still the chief cause of death in most developed and developing countries. ${ }^{12,} 13$ The present cardiac markers are not sufficiently sensitive at an early stage of ACS. That's why an early and reliable marker is needed for accurate diagnosis of ACS. Platelet parameters especially PDW could be an important and reliable markers in early detection of ACS when other markers are not available. Because platelet activation is the preliminary steps of ACS; and PDW indirectly indicate the status of platelet. ${ }^{11,12}$

In our study, we found that ACS was associated with increase PDW. The study reveals that the mean $( \pm \mathrm{SD})$ value of PDW was significantly higher in patients with ACS than controls. Similarly MPV also increases but platelet counts were lower in ACS that means inverse proportion to platelet count and PDW and MPV. Smith $\mathrm{NM}^{14}$ observed increase PDW and MPV are index of platelet size and correlates with platelet activation, and also a reliable index of platelet activation, may be a potentially useful marker in cardiovascular risk stratification described a study done by Martin JF. ${ }^{15}$

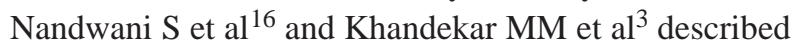
in their studies all platelet volume indices including MPV, PDW and platelet large cell ratio (P-LCR) were increased significantly in patients with ACS than controls. Varol E et $\mathrm{al},{ }^{17}$ Cemin $\mathrm{R}$ et al ${ }^{18}$ and Yilmaz et al ${ }^{19}$ also found that MPV was significantly higher in patients with ACS groups than controls, along with reverse changes in platelet count.
Similar findings found study done by, Mercan $\mathrm{R}$ et $\mathrm{al}^{7}$ and Ranjith MP et al. ${ }^{20}$ They found platelet counts were significantly lower in the ACS groups as compared to control subjects, but MPV was significantly higher in ACS.

There are many studies done where platelet volume had association with ACS. Chu SG et $\mathrm{al}^{21}$ described MPV as a risk factor and prognostic indicator in cardiovascular disease. Lippi $G$ et $\mathrm{al}^{2}$ found in their study MPV was significantly associated with ACS than with non-ACS. Previously there was no study on validity tests of platelet counts and PDW as known to us. There were only two studies found on values of platelet count and PDW and few studies on MPV. Here with findings of platelet count and PDW sensitivity and specificity in our study will enrich diagnostic modalities in patients with ACS. The sensitivity, specificity, positive and negative predictive values were determined through ROC curves against troponin I. In our study among the 79 cases, 53 were troponin I positive and 26 were troponin I negative. All of the control subjects were troponin I negative. According to diagnostic criteria 67 cases were diagnosed as AMI and 12 cases were UA where troponin I was negative. Among 67 AMI cases, only 53 cases were troponin I positive and 14 cases were initially troponin I negative and became positive later.

In case of PDW and MPV, we found significant differences between the groups. There are two hypotheses that described the increased these parameters. First, when platelet activated they change their size and shape (metamorphosis). Second, after platelet activation aggregation of more platelet this leads to release of younger platelet from bone marrow. These suggest that MPV and PDW are indirect indicators of platelet activation and their association with ACS. Among the platelet parameters PDW was most significant than MPV. These findings lead to the hypothesis that larger platelets as determined by their volumes, MPV and PDW may be useful markers in patients with ACS. Our data indicate that, higher PDW may become useful marker for early detection of ACS along with other biomarkers.

\section{Conclusion:}

The metamorphic platelets are haemostatically more active and trends to developing coronary thrombus formation leading to ACS. Patients with increased PDW could be identified easily and play an important role in early diagnosis of ACS and early initiation of anti-platelet therapy. There by prevention and development of fullblown of ACS. It could be used as a screening test of ACS from other non cardiac chest pain, and severity and prognosis of ACS. 
Limitation and recommendation of the study: The study was done in limited time of span and no comparison with angiographic findings. Further studies are required to assess whether PDW provide beneficial role to identify patients at early stages of ACS, clinical risk and whether therapeutic modification of this marker may lead to improved cardiovascular risk.

\section{References:}

1. Lippi G, Montagnana M, Salvagno GL, Guidi GC. Potential value for new diagnostic markers in the early recognition of acute coronary syndromes. CJEM 2006; 8:27-31.

2. Lippi G, Filippozzi L, Salvagno GL, et al. Increased mean platelet volume in patients with acute coronary syndromes. Arch Pathol Lab Med 2009; 133:1441-3.

3. Khandekar MM, Khurana AS, Deshmukh SD, et al. Platelet volume indices in patients with coronary artery disease and acute myocardial infarction: an Indian scenario. J Clin Pathol 2006; 59:146-9.

4. . Endler G, Klimesch A, Sunder-Plassmann H, et al. Mean platelet volume is an independent risk factor for myocardial infarction but not for coronary artery disease. Br J Haematol 2002; 117:399_ 404.

5. Davì G, Patrono C. Platelet activation and atherothrombosis. N Engl J Med 2007; 357:2482-94.

6. Sabatine MS, McCabe CH, Cannon CP. Design and rationale of clopidogrel as adjuctive reperfusion therapy (CLARITY)thrombosis in myocardial infarctio (TIMI) 28 trial. Am Heart J 2005; 149:227-33.

7. Mercan R, Demir C, Dilek I, Asker M, Atmaca M. Mean platelet volume in acute coronary syndrome. Van Týp Derg 2010; 17(3):89-95.

8. Yetkin E. Mean platelet volume not so far from being a routine diagnostic and prognostic measurement. Thromb Haemost 2008; 100:3-4.

9. Ruggeri ZM. Platelets in atherothrombosis. Nat Med 2002; 8:1227-34.

10. Vagdatli E, Gounari E, Lazaridou E, Katsibourlia E, Tsikopoulou 3, Labrianou I. Platelet distribution width: a simple, practical and specific marker of activation of coagulation. HIPPOKRATIA 2010; 14 (1):28-32.
11. Chu Hsin, Chen WL, Huang CC, Chang HY, Kuo HY, Gau CM, Chang YC, Shen YS. Diagnostic performance of mean platelet volume for patients with acute coronary syndrome visiting an emergency department with acute chest pain: the Chinese scenario. Emerg Med J 2011; 28: 569-74.

12. Assiri AS, Jamil AM, Mahfouz AA, Mahmoud ZS, Ghallab M. Diagnostic importance of platelet parameters in patients with acute coronary syndrome admitted to a tertiary care hospital in southwest region, Saudi Arabia. J Saudi Heart Assoc 2012; 24 (1):17-21.

13. Akanda MAK, Ali S, Islam AEMM, Rahman MM, Parveen A, Kabir MK, Begum L, Barman RC. Demographic Profile, Clinical Presentation \& Angiographic Findings in 637 Patients with Coronary Heart Disease. Faridpur Med. Coll. J. 2011; 6 (2): 82-85.

14. Smith NM, Pathansali R and Bath PMW. Platelets and stroke. Vasc Med 1999; 4:165- 172.

15. Martin JF, Bath PM, Burr ML. Influence of platelet size on outcome after myocardial infarction. Lancet 1991; 338:1409-11.

16. Nandwani S, Bhatnagar M, Gaur S, Kumar M. Study of Platelet Volume Indices in Patients of Acute Coronary Events. Journal of The Indian Academy of Geriatrics 2011; 7: 22-24.

17. Varol E, Icli A, Ozaydin M, Erdogan D \& Arslan A. Mean platelet volume is elevated in patients with myocardial infarction with normal coronary arteries, as in patients with myocardial infarction with obstructive coronary artery disease. Scandinavian Journal of Clinical \& Laboratory Investigation 2009; 69(5):570-74.

18. Cemin R, Donazzan L, Lippi G, Clari F and Daves M. Blood cells characteristics as determinants of acute myocardial infarction. Clin Chem Lab Med 2011; 49(7):1231-36.

19. Yilmaz MB, Cihan G, Guray Y, Guray U, Halil LK, Sasmaz H, Korkmaz S. Role of mean platelet volume in triagging acute coronary Syndromes. J Thromb Thrombolysis 2008; 26: 49-54.

20. Ranjith MP, Divya R, Mehta VK, Krishnan MG, Raj RK, Kavishwar A. Significance of platelet volume indices and platelet count in ischaemic heart disease. J Clin Pathol 2009; 62: 830-33.

21. Chu SG, Becker R C, Berger P B, Bhatt D L, Eikelboom JW, Konkle B, Mohler E R, Reilly MP and Berger JS. Mean platelet volume as a predictor of cardiovascular risk: a systematic review and meta-analysis. Journal of Thrombosis and Haemostasis 2010; 8: $148-56$. 